\title{
Biotechnological

\section{Effect of rat cartilage essence on omentum cells cultured through micromass method}

\author{
Zahra Goudarzi ${ }^{1}$, Kazem Parivar ${ }^{2}$, Susan Kiaei ${ }^{*}$ and Roudabeh Razaz ${ }^{4}$ \\ ${ }^{1,3,4}$ Master of Biology, Department of Biology, Science and Research Branch, Islamic Azad University, \\ Tehran, Iran \\ ${ }^{2}$ Department of Biology, Science and Research Branch, Islamic Azad University, Tehran, Iran
}

\begin{abstract}
Omentum`s tissue MSCs have recently been recognized as multipotent cells. In this study inducing effects of cartilage essence obtained from the NMRI bred rat on omentum cells cultured through Micromass method have been evaluated. 12 days NMRI rats were used as cell sample. Omentum tissue lacking fast was removed from the intestines. To culture in cellular compressed mass through micromass, cells numbers were added in level unit. Before culturing, cells were precipitated at the bottom of the tube like a compressed mass by centrifuge and then DMEMculturing environment containing glutamine, glucose and sodium pyruvate, without sodium B carbon was added to the resulted cellular mass. Furthermore, FBS serum amount was reduced to 2\% in culturing environment gradually. Thereafter, stem cells were exposed to various doses of cartilage essence. Investigations showed that density rate of cartilage essence 50 Landa were able to ease the process of turning to cartilage for these cells in 21 days. Cartilage essence's other densities have led to the elimination of stem cells. To prove the differentiation of mesenchymal cells chondroblast turn, Alison blue and Toluidine blue which are the specific colors of outer cellular matrix was used.
\end{abstract}

KEY WORDS: MESENCHYMAL CELLS, OMENTUM TISSUE, STEM CELLS, CARTILAGE ESSENCE, CHONDROBLAST, DIFFERENTIATION

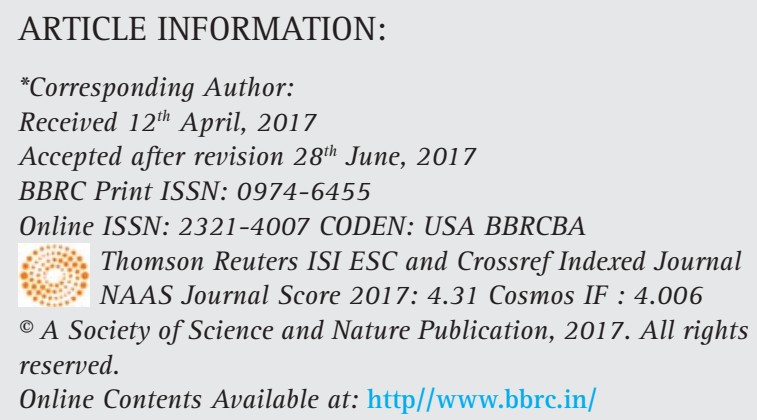




\section{INTRODUCTION}

Stem cells are a kind of an undifferentiated somatic cell which have two unique characteristics: Self-renewal: which they can continuously replicate themselves in culturing environment and maintain their restoration for an infinite period. Differentiation: which they can under certain conditions turn into specified cells and differentiate other constructing cell type's pf a living body. These cells exist in blood, bone marrow, skeletal muscle, retinal, retina, teeth pulp, brain, nerve cord, liver, skin, intestine, pancreas and venous blood (Kadivar, M., 2009). Regarding replication and differentiation potential, stem cells with different sources are different in a way that this potential decreases from embryonic stem cells to adult's stem cells (Baksh, 2004).

Despite embryonic stem cells high potential, their use due to problems related transplant rejection of the cells, ethical problems and tumorigenicity of these cells after transplant is highly limited (Romanov, 2003). Unlike embryonic stem cells, MSCs are not replicated permanently whereas after some time face senescence. Studies showed that cell replication in lab environment leads to the decrease of their differentiating replication ability process (Baqban et al. 2008). Till today stem cells functions included genomics studies, biological processes studies and development of cell treatment. Currently scientists use stem cells for screening of new medicines in labs. (Toyooka, 2003). Methods of identifying primary MSCs are diverse. Flowcytometry is based on the MSCs reaction to a number of antibodies (Alagumuthu, 2006, Chapel, 2003, Liu,2010).

Previous researches have proved the flexibility of stem cells differentiated from nerve cell, skin cover, lung, liver, intestine, kidney, and spleen. (Evans, 2002, Martin 2003). Studies showed that MSCs, when cultured in a 22 monolayer fashion, show lesser Chondrogenic differentiation compared to $3 \mathrm{~d}$ culturing. We believe that cell when culturing in 3D fashion (cellular mass) experiences a similar environment to precartilage environment in embryonic genesis period (Johnstone,1998). Under these condition chondrocytes maintain their cartilage phenotype. It seems that the main reason of cartilage phenotype maintenance in micromass culturing is the cellular reaction due to direct cell to cell contact in cellular mass. Omentum is a big peritoneal wrinkle. From omentum's special features we can refer to its rich source of angiogenic factor, having a strong lymphatic system, having the ability to produce security specialized cells and a big source of various growth factors such as neurotransmitters, neurotrophic factors and inflammatory mediators. Furthermore, it includes multipotent stem cells which can differentiate between various types of cells (Carlos 1992, Khaluqi, 2011).
Various ways can be considered for creating directed differentiation in lab environment which can include adding growth factor(s) or chemical morphogens (Li, wg; 2005), co-culturing of stem cells with inducing cells, stem cells transplant to certain regions or organs and etc. In this research project cartilage essence effect on omentum MSCs differentiation toward cartilage cells in micromass culturing with gradual reduction of the serum is investigated.

\section{MATERIAL AND METHODS}

In this research 12 days NMRI bred rat, ranging between 18-22 gms, were used as test animals. All the dilutions used in this article wereprovided though commerce and were used without further purification. Purchased culturing environment was DMEM (Dulbeccos Modified Eagles Medium-high glucose), containing glutamine, glucose sodium pyruvate, without sodium bicarbonate from Royan Stem Cells technology Co. FBS dilution which contains required proteins and factors for cell growth, was produced from cow serum. PBS without calcium and magnesium ions was provided with its $\mathrm{PH}$ domain within the range of 7.2 to 7.4. All the dilutions used in culturing such as PBS, DMEM, and FBS were sterile before use by passing through syringe head filter with 0.22 micrometer penetrative diameter.

First under the laminar hood wish disinfected using UV and alcohol 10ml PBS dilution was poured into $10 \mathrm{~cm}$ Petri dishes. Then, a couple of pen strep drops (penicillin and streptomycin dilution) were added. In animal room a rat was made unconscious and was transferred to the surgery bed. Using $70 \mathrm{Ct}$ alcohol all of its body especially its stomach surface was disinfected and stomach's wall and peritoneum were exposed using scissors and stretching stomach to the sides. Then, using forceps and scissors omentum tissue lacking fat was removedfrom intestines. Omentum tissues placed on ice were washed using cool PBS dilution containing 1\% penstrep three times so that it became blood cell free, cellular wastes and any other possible pollution free. Thereafter, omentum tissues were gathered in a new Petri dish containing sterile DMEM, using scissors fragmented and then centrifuged.

Common technique for chondrogenic differentiation of MSCs in lab environment through micromass method was derived from Johnstone et al., method (Johnstone et al.,1998). In this technique, to simulate differentiation environment in a natural way in embryo, a greater number of cells were exposed to the essence in falcon in a compressed fashion in a way that 250000 to 300000 in 500 landa of culturing environment were added using centrifuge with $1200 \mathrm{rpm}$ for 5 minutes in a compressed fashion slowly at the bottom of the falcon. Also, FBS 
serums amount in culturing environment was reduced gradually. Meaning when changing culturing environment, each time a lesser amount of FBS were added to DMEM. Therefore, cells were cultured with 2\% FBS

Almost 24 hours after the birth of rat, their stemum cartilage tissue was removed and were homogenized and centrifuged. We discard the above dilution and a specific amount of nitrogen was added tp cartilage parts deposited, inside a rocky pounder. Due to sudden reduction of cartilage parts temperature, in its matrix of mid-cellular tissue crystals are formed which leads to easy fragmentation by the pounder. We added $4 \mathrm{ml}$ DMEM containing FBS15\% to the easily fragmented cartilage parts. Now we homogenize them with high rmp to obtain a suspension of cartilage. It will take 5 to 7 minutes. Then we transfer to centrifuge and centrifuge it with 700rpm. We remove the above dilution and filter it with 0.45 micrometer syringe head filter. Dilution withdrawn is cartilage essence. Five groups were studied. Respectively, observer which only contained culturing environment with 10\% serum, free group or without serum and falcons with various doses, with doses of 20, 40, and 50 landa which serum amount in each of the gradually was reduced to $2 \%$ and placed in incubator for 21 days.

Densities for obtaining $1000 \mu$ l or 1cc culturing environment are as follows in thistest. (For 1cc differentiating material prepared, $0.1 \mathrm{ml}$, pen/strep is added to the environment).

- Observer (10\%FBS + 90\%DMEM) 1000 $\mu \mathrm{l}$

- Environment without serum (100\%DMEM) $1000 \mu \mathrm{l}$

- 20 landa dose $20 \mu$ (cartilage essence) $+(2 \%$ FBS + 98\%DMEM) $980 \mu \mathrm{l}$

- 40 landa dose $\quad 40 \mu$ (cartilage essence) $+(2 \%$ FBS + 98\%DMEM) $960 \mu \mathrm{l}$

- 50 landa dose $\quad 50 \mu$ (cartilage essence) $+(2 \%$ FBS + 98\%DMEM) $950 \mu \mathrm{l}$

To prove chondroblast differentiation of mesenchymal cells we use Alison Blue and Toluidine Blue coloring which are the specific colors of outer cellular matrix. To color differentiated cells with Alison blue and Toluidine bluw, first cells were fixed with formaldehyde fixator. To color with toluidine blue, after consolidation, watering with alcohol and clarification with xylene, are molded by paraffin and 5 micrometer cuts are taken from them. Toluidine blue is treated to cellular plates for 30 seconds in room temperature with 50 landa cartilage essence and in the end extra color is washed off with distilled water.

To color with Alison blue, 0.1 Alison blue color is diluted in 10ml PBS with the help of PHmeter and adding normal hydrochloric acid 0.01 its $\mathrm{PH}$ is determined in the range of 6 to $6 / 5$. Thereafter it was added to the cellular plated treated with 50 landa cartilage essence and were incubated for an approximately one hour.
In the end we discarded the dilution on the cells and washed them with PBS dilution and scanned them. To prove the existence of chondroblast cells with immunohistochemistry test after tissue consolidation and preparation, molding with paraffin was performed. After providing levels, clarification and watering, levels consolidation was performed by sten. To neutralize peroxide activity of inner tissue hydrogen, samples were placed in 3 percent hydrogen peroxide for 30 minutes. To reveals antigens, pepsin enzyme with the amount of $1 \mathrm{mg}$ in $1 \mathrm{ml}$ acetic acid $0.5 \mathrm{~m}$ for 40 minutes in $37 \mathrm{cc}$ degree was used. Thereafter samples were incubated in primary antibodies against collagen molecules of rat type II for 24 hours in 4cc degree. In the next stage, secondary antibody connected to polymer containing horseRadish peroxidase, were added to the samples and after washing them with PBS buffer, di-amino benzidie chromogen was added to the samples. To color the background, hematoxylin was used. After washing the samples with buffer, study was conducted by microscope.

\section{RESULTS AND DISCUSSION}

One of the ways of identification and assertion of mesenchymal nature of cells is using cell surface markers. Flowcytometry analysis of CD45 is negative and for CD44 and CD90 is positive. Therefore, mesenchymal nature of created cells from omentum is confirmed.

\section{PERCENT OF MARKERS}

Omentum: A) CD90 Antibody in 84.5 percent of the analyzed cells is expressed. B) CD45 antibody which only in approximately 1.92 percent of analyzed cells is expressed. C) CD44 in 88.22 percent of the cells were expressed.

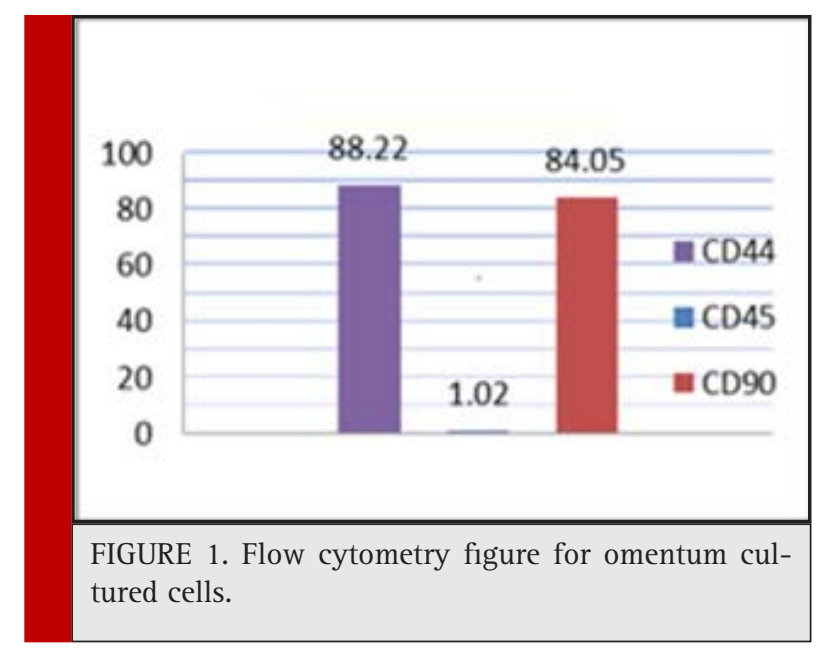




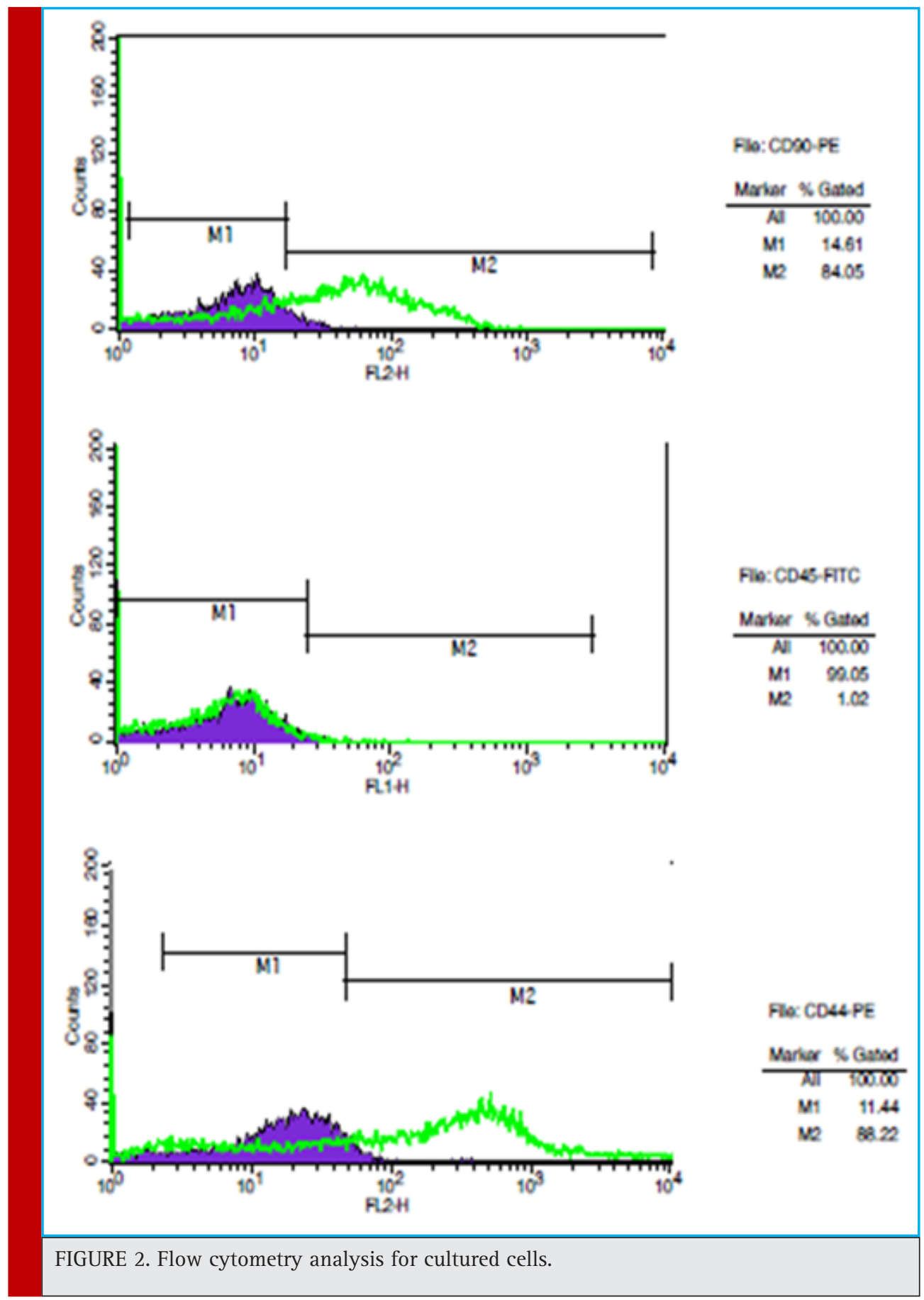

In the current study RNA samples were extracted from omentum cultured cells and inverted transcription reaction was performed using designed starters. In this test, we used WT-1 gene as the marker of mature stem cells and 0ct-4 as the marker of embryonic powerful cells, and ACTB gene as the house keeper (this gene is always expressed, if not it is an indication of incorrect use of PCR). Observations showed that in this test both WT- 1 and Oct- 4 genes are expressed, however, RT-PCR band related to MRNA with WT-1 gene was brighter and clearer than RT-PCR band related to mRNA with 0ct-4 gene. Therefore, WT- 1 and 0ct- 4 gene expressions are proof of stem cells existence in omentum.

Cellular mass enlargement shows that cells discharge matrix among themselves and created cartilage tissue. To prove this claim, after the end of 21 days of differentiation, we performed sectioning on the samples. Investigations was carries out by microscope and colored by 


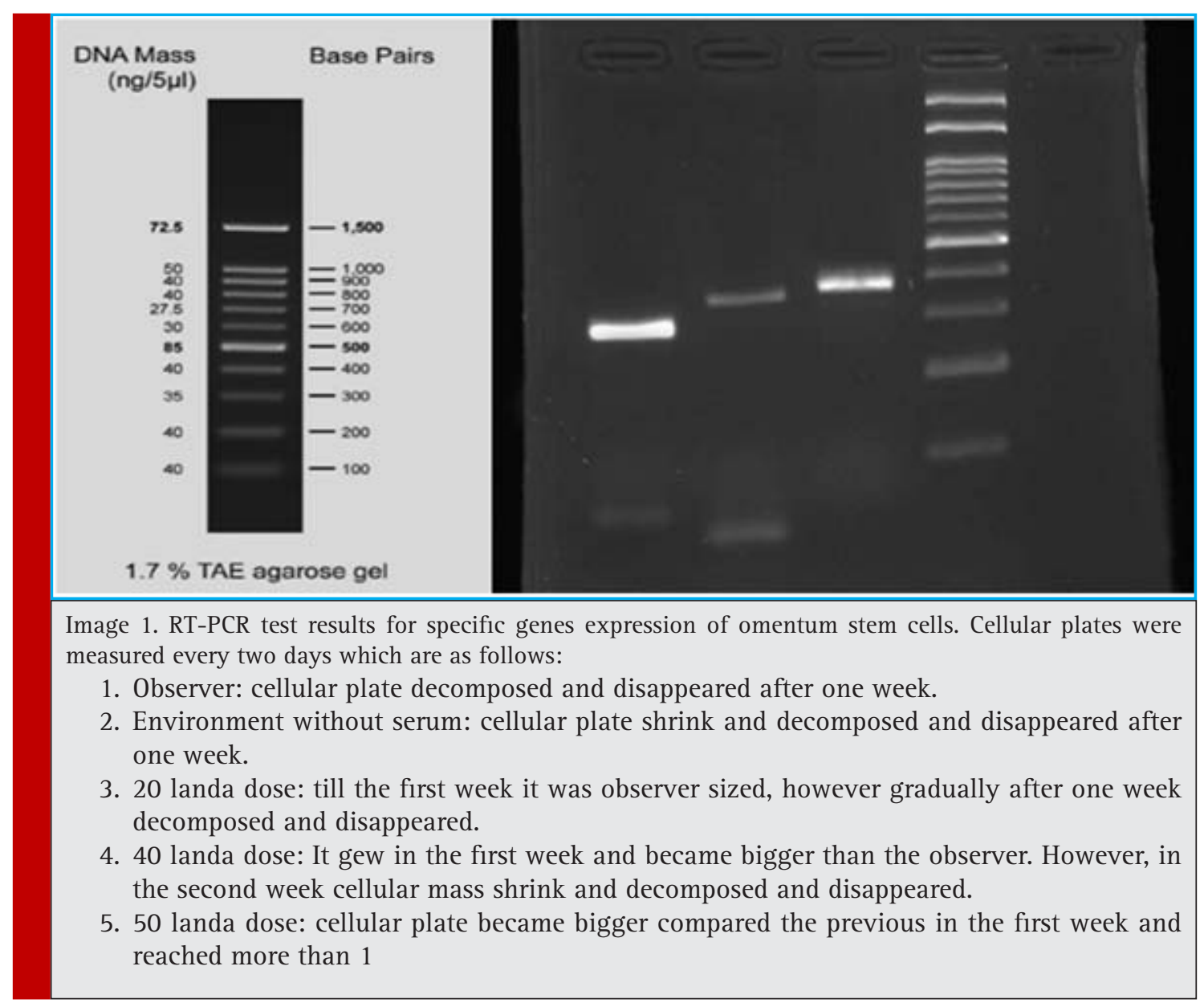

Alison blue and Toluidine blue and Collagen 2 expression was investigated by immunohistochemistry.

Microscopic investigations showed that with serum reduction better differentiation occurs and chondrocytes affected by the cartilage essence with 50 landa dose showed better morphology. Following images confirm these claims.

Colored sections with toluidine blue show metachromatic characteristic and background material turns into purple.

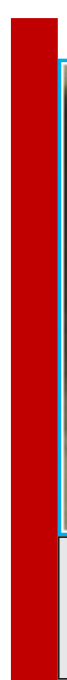

a

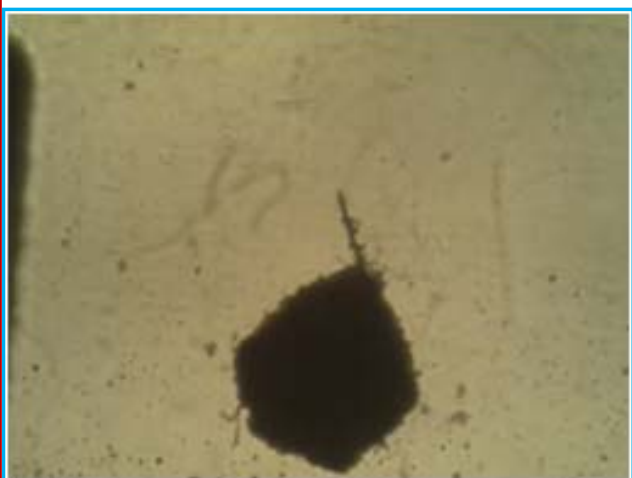

IMAGE 2. Images are related to omentum mesenchymal cells cultured through 3D culturing method after cartilage effect with the amount oof 2\% FBS serum. a) 20 landa dose of cartilage essence after one week. b) 40 landa dose of cartilage essence after one week. 


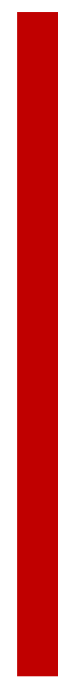

a

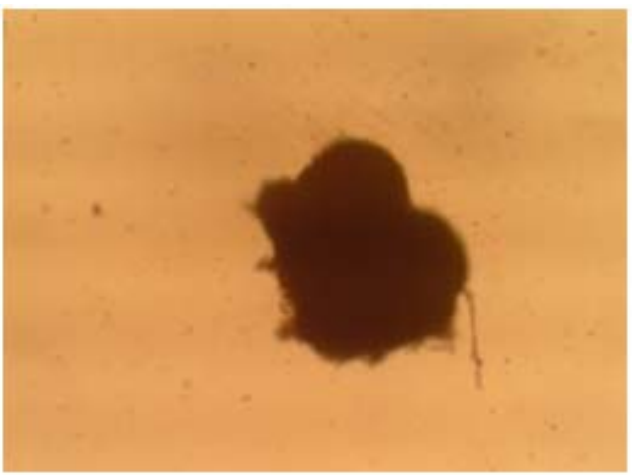

IMAGE 3. Images related to cultured omentum mesenchymal cells through 3D culturing method after the cartilage essence effect with 50 landa dose and amount of 2\% FBS. a) After one day which as big as observer group. b) After one week which is slightly bigger. b

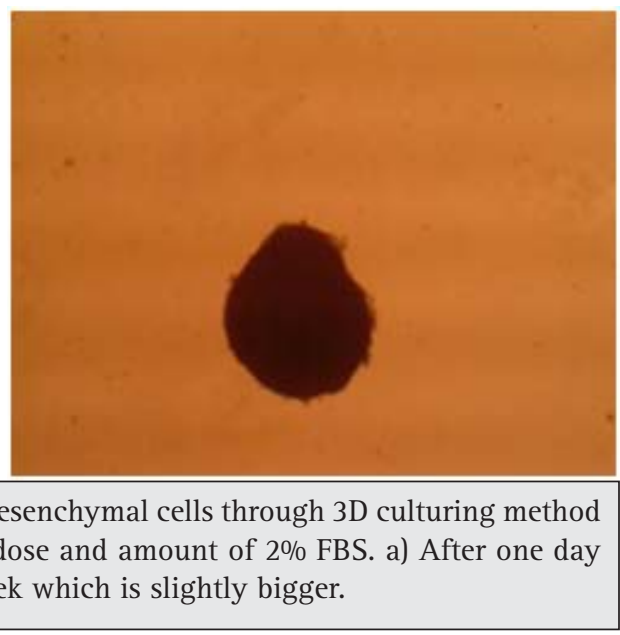

b

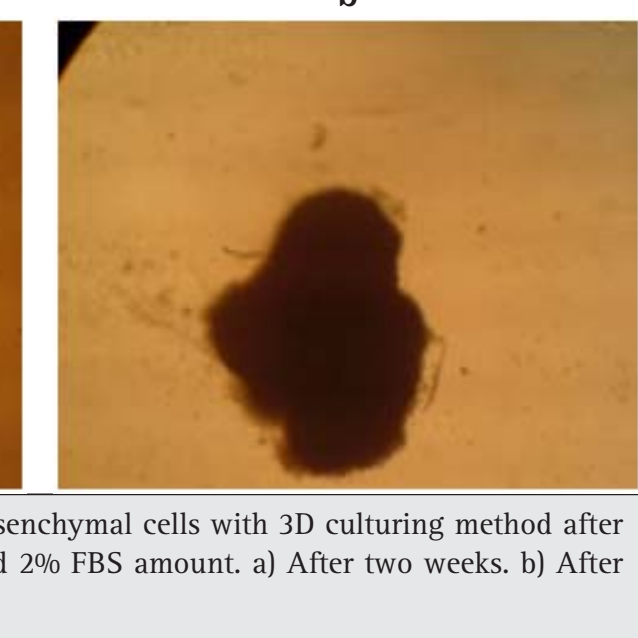

IMAGE 4. Images related omentum cultured msenchymal cells with 3D culturing method after cartilage essence effect with 50 landa dose and 2\% FBS amount. a) After two weeks. b) After three weeks.

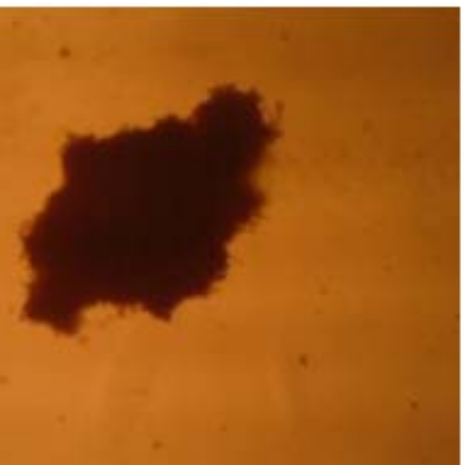

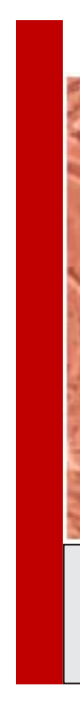

a
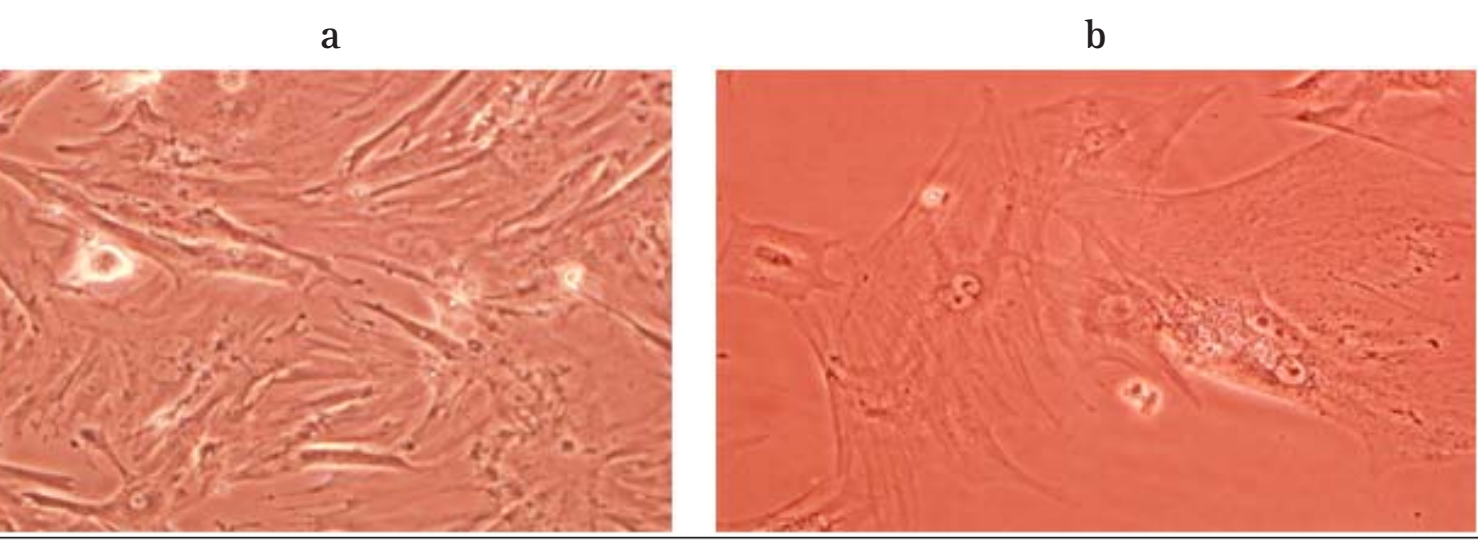

IMAGE 5. Image is related to omentum mesenchymal cells 21 days after the cartilage essence effect with 50 landa dose and 2\% FBS. a) Dual and ternary cells are completely visible in clear lacuna halo. b) Cells differentiation are completely obvious. 


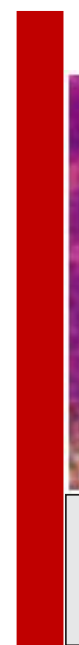

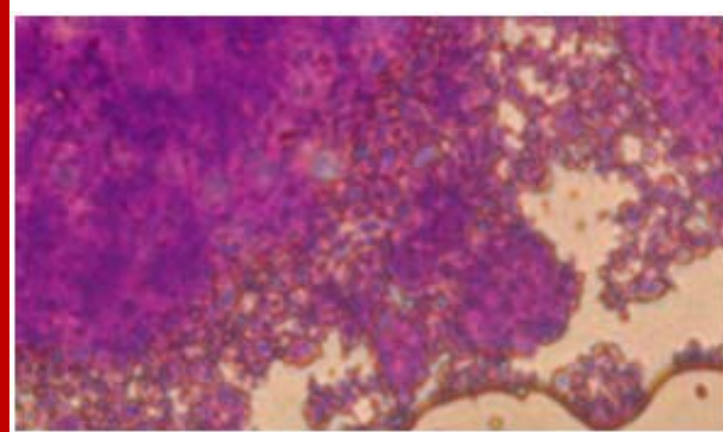

b

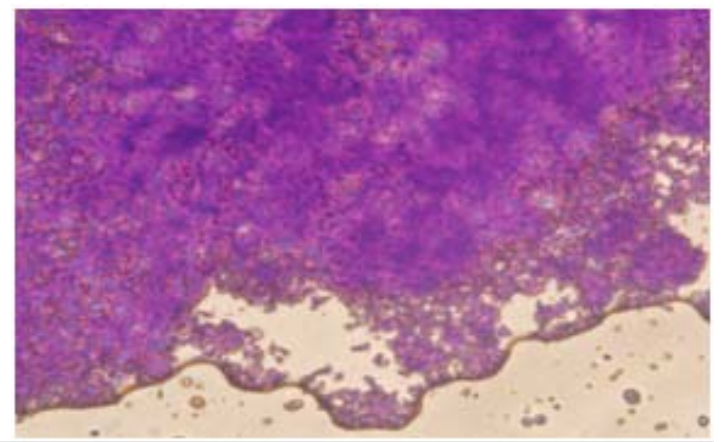

IMAGE 6. Image is related to 3D culturing section 21 days after cartilage essence effect with 50 landa dose and 2\% FBS serum. After coloring with toluidine blue, cells round morphology and their dark core is visible in image $b$.

In coloring with Alison bluematerial finds a bluish green background. Image 6: Image is related to the DC culturing section 21 days after cartilage essence effect with 50 landa dose and 2\% FBS serum. After coloring with Alison blue, a community of cells which that have turned into a colony and discharged matrix among themselves is seen. To investigate the expression of Collagen type 2, primary and secondary antibodies which are anti- collagen type 2 are used in the cartilage differentiated cells, which the results are visible in the following images.

Stem cells are a kind of undifferentiated somatic cells that are found in the majority of the multicellular liv- ings. Some of their characteristics are self-renewal ability, high mitotic distribution and differentiation power toward different types of specified cells (Becker, 1963, Siminovitch, 1963). We can refer to MSCs as one of the most important mature stem cells that have attracted researcher's attention. Omentum mesenchymal cells play a role in treating damages and it was identified in 1948 by Cannaday for the first time (Kadivar, 2009). These cells are utilized as supporting cells for inner growing organs in vivo conditions (Iwashima, 2011). Recently extracting MSCs from omentum tissue is carried out successfully (Alagumuthu, 2006, Singh, 2008). In this study too, first omentum mesenchymal cells of 12 days

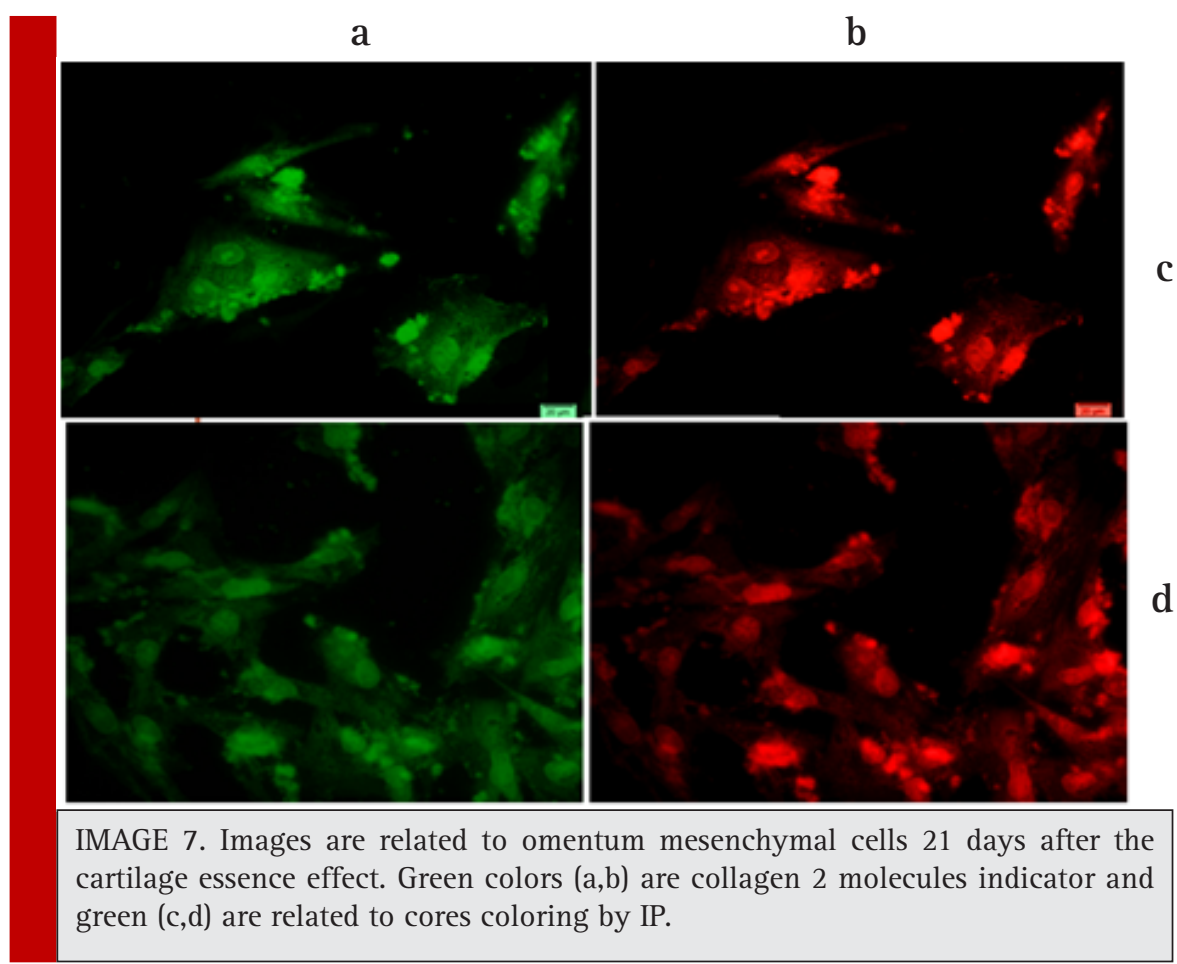


NMRI ratis extracted and summarized. Some lab studies have shown that if mature chondrocytes are cultured in simple dishes, lose their differentiation rapidly and their physiological activities decrease ( $\mathrm{Ng}$ 2005). One of the important conditions for creating culturing is using micromass (Johnstone,1998). Weused this method for creating suitable cellular mass, which is increasing number of cells in level unit.

Thereafter, cells phenotype and genotype was confirmed with various evaluations such as flow cytometry. Accordingly, in human and other rodents such as rat, surface antigens related to these cells were investigated by flow cytometry and using monoclonal antibodies. What today is important in identification of MSCs, is if they have fibroblast morphology and are negative in terms of hematopoietic stem cells, they can be presented as MSCs (Barry, 2004). Expressing specific markers of MSCs includes CD90 and CD44 and lack of expressing special marker of hematopoietic cells is confirmed as CD45 in separated cells from the omentum, which is aligned with Pancholi et.al results (Pancholi et al $2010 \mathrm{Li}, 2005$ ).

In this research cartilage essence was used for creating differentiation induction instead of using common growth factors, since using growth factors such as TGF $\beta$ can have unknown effects on other cells and have tumorigenic effects. However, using natural essences in addition tolacking the above mentioned shortcomings can have the advantage of lesser transplant rejection due to tissue similarities and cells differentiate with more similar conditions with their natural den. Treatment with cellular essence, is a new strategy for cells differentiation which is able to transform a type of somatic cell into another. MSCs affected by cartilage essence induction can find chondrocyte cells morphology. For instance cells took an oval shape which is a characteristic of chondrocyte cells (Shamblott, 1998). Then matrix construction begins to separate chondroblasts. Differentiation occurs from the center toward exterior. Therefore, more central cells have chondrocytes characteristics, however, ambient cells typically are chondroblasts (Liu, 2010).

Various dilutions of cartilage essence were used, after mesenchymal cells were treated by cartilage essence with 50 landar dose, significant changesoccurred from the fourth day onward. In some regions cellular colonies were created. With an increase in number of cells, they absorb cellular extras. And cells move toward oval and round formation, which means they are chondroblasts which later use of specific Alison blue and Toludine blue coloring confirmed this notion. These cells seem completely alive and active and replication process still continues in them. These change occur while in other groups under study, their cells still remain between chondrocytes morphology phase and spindly and lengthy mor- phology which is specific tp fibroblasts and with passage of time face senescence and apoptosis.

Collagen type 2 is the most abundant existing collagen in cartilage. Collagen type 2 contains specific sequences to connect to the cell and as a result has a high interaction with the cell. It can be suitable for maintaining cartilage cells phenotype and activities ( $\mathrm{Li}$, 2005, Zambrano, et al, 1982). In this experience we were able to confirm production of collagen type 2 through immunohistochemistry in cartilage cells derived from omentum MSCs of NMRI breed rat after 21 days from the start of differentiation induction. Therefore, considering cellular mass and morphological changes in the cultured stem cells it seems that we succeeded in producing chondroblasts.

\section{CONCLUSION}

This research is carried out to investigate inducing effects of cartilage essence obtained from rat on culturing omentum cells through micromass with reducing serum amount and understanding and interpreting the results. Results are the indication of the cartilage essence effect on omentum's MSCs in the absence of growth factors, common induction and their differentiation with chondrocytes. It seems that our method of separating omentum's mesenchymal cells and producing cellular lnie was completely successful and powerful and have appropriate and acceptable progress toward differentiation, specially creating a compression and production of chondroblasts. Considering the results that Dubler et.al have obtained from culturing on collagen and results that Tuli and Okafor obtained regarding culturing with tissue engineering using collagen type 2, we can conclude that the cartilage essence used in this research as an induction factor can intensify differentiation process in cells due to existence if collagen in itself with the help of creating and maintain cellular connections.

\section{REFERENCES}

Alagumuthu, M., Das, BB., Pattanayak, SP., Rasananda, M., 2006, The omentum: A unique organ of exceptional versatility, Indian J Surg; 68:136-41.

Baksh, D., Song, L., Tuan, R.S, 2004, Adult mesenchymal stem cells: Characterization, differentiation and application in cell and gene therapy, J. cell. mol. Med, vol 18, No 3, 301-316

Baqban Eslami Nejad, M, Talkhabi, M, Zeynali, B, Eftekhari Yazdi, P, 2008. Investigating Lithium chloride on replication rate of MSCs derived from rat's bone marrow. Year 6. Issue 23. Pages 363-372

Barack Johnstone, T.M. Hering, A.I. Caplan etal.,1998 Invitro chondrogenesis of bone marrow-derived mesenchymol progenitor cells, Exp Cell Res, Vol. 238, no.1, PP. 265-272, 
Barry, F-P-, Murphy, J.M., 2004, Mesenchymal stem cells: clinical application and biological characterization, The international journal of biochemistry \& cell Biology 36:568584

Becker, A.J., Mcculloch, E.A., Till, J.E., 1963, Cytological demonstration of the clonal nature of spleen colonies derived from transplanted rat marrow cells, Nature; 197:452-4

Carlos Junquera, L, jose carneiro, Robert. O.K: (1992), Basic histology

Chapel, A., Bertho, JM., Bensidhoum, M., Fouillard, L.,Young, R.G., 2003, Mesenchymal stem cells home to injured tissues when co-infused with hematopoietic cells to treat a radiationinduced multi-organ failure syndrome, J Gene Med; 5(12): 1028-38

Evans, MG., Kaufman, MH., Establishment in culture of Pluari potential Cell from rat embryos. Nature (2002) 2, 2 : 154-156

Gomez, I., 2012, Omentum in the Repair of Injured Tissue: Evidence for Omental Stem Cells,stem Cells and Cancer Stem Cells, Volume 2

Iwashima, M., Love, R., Braun, R., Sethupathi, P., Knight, K.L., 2011, Omentum as a source of stromal/ stem cells and medical treatments using stroma) stem cells, Patent Application publication

Jones, EA S.E. Kinsey, A. English et al., Isolation and Characterization of bone marrow multipotential mesenchymol progenitor cells, Arthritis Rheum, Vol. 46, no.12, PP. 3349-3360, 2002

Kadivar, M. Piryiayi F and Ramezani, M. 2009. Separation, culturing and MSCs differentiation of chickens bone marrow. Journal of Armaqan Danesh. Round 14. Issue 4

Khaluqi, K. Shahbazi, A. Sojoudi, M. Vosouq, M. 2011. Stem cells in simple language. Tehran. House of Biology. First Volume

Li, WG Tuli, R; Okafor, C A three -dimensional nanofibrous scaffold for cartilage tissue engineering using human mesenchymal steem cells Biomaterials, (2005)
Liu, Y., Yue, W., Ji, L., Nan, X., Pei, X., 2010, Production of erythriod cells from human embryonic stem cells by fetal liver cell extract treatment, BMC Developmental Biology; 10:85

Martin GR. 2003 Isolation of a Pluripotent Cell line From early rat embryos cultured in medium conditioned by teratocarcinoma Stem cells . Proc . Natl . Acad . Sci, 78: 7634-7638

Ng, S., Wua, Y.N., Zhou, Y., Tohb, Y.E., Ho, Z.Z., Chia, S.M., 2005, Optimization of 3D hepatocyte culture by controlling the physical and chemical properties of the extra- cellular matrices, Biomaterials; 26(16) :3153-3163

Pancholi, N., Patel, J., Gudehitblu, K., Kraus, M., Dunea, G., Arruda, J., Singh, AK., 2010, Culture of omentum-induced regenerating liver yielded hepatocyte-committed stem cells, Tranalation Research, Voiume 156, Number 6; 156(6):358-68

Pournasr, B. Baharvand, H. 2010. Stem cells and human`s msenchymal: biological characteristics, treatment functions and separation methods. Tehran. House of Biology. Volume 2. 28-67

Romanov, YA., Swvintsitskaya, VA., Smirnov, VN., Searching for alternative Sources of postnatal humar mesenchymal Stem cells: candidate MSC like cells from umbilical cord. Stem Cells (2003) $21: 105-110$

Shamblott, MJ., Axelmanj, J., 1998 Derivation of pluripotent stem cells from Cultured human primordial germ cells. Proc Natl Acad Sci, (1998).

Siminovitch, L., Mcculloch, E.A., Till, J.E., 1963, The distribution of colony-forming cells among spleen colonies. Journal of cellular and comparative physiology; 62:327-36

Singh, A.K., Patel, G., Litbarg, N.O., Gudehithlu, H.P., Sethupathi, P., Arruda, G.A . and Dunea, G., 2008, Stromal cells cultured from omentum express pluripotent markers, produce high amount of VEGF and engraft to injured sites. Cell and Tissue Research, 332:81-88

Toyooka, Y; Tsunekawa, N; Akasu, R; 2003 Embryonic stem cells can from germcells in vitro.

Zambrano, NZ; et al. collagen arrangement in cartilages Acta Anat (1982). 113:26 